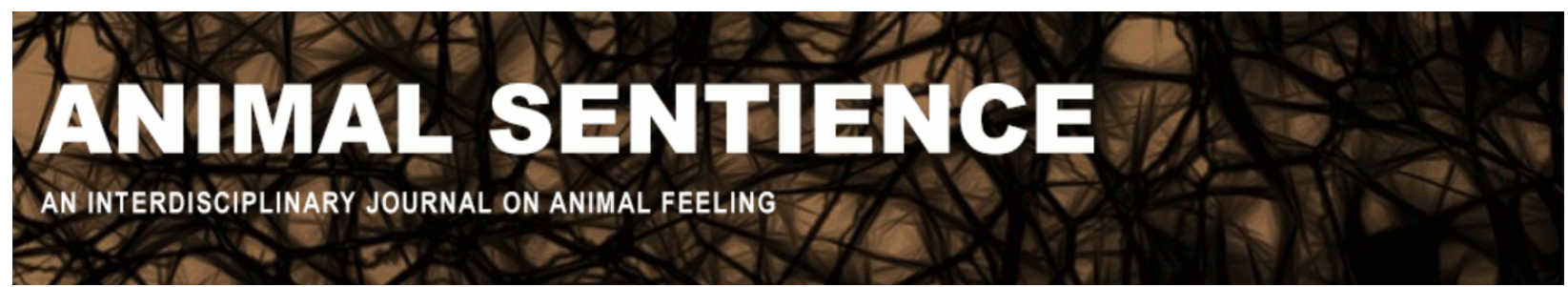

Monsó, Susana and Osuna-Mascaró, Antonio J. (2020) Problems with basing insect ethics on individuals' welfare. Animal Sentience 29(8)

DOI: $10.51291 / 2377-7478.1589$

Date of submission: $2020-06-14$

Date of acceptance: 2020-06-15

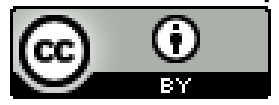




\title{
Problems with basing insect ethics on individuals' welfare
}

Commentary on Mikhalevich \& Powell on Invertebrate Minds

\author{
Susana Monsó \\ Messerli Research Institute \\ University of Veterinary Medicine Vienna \\ Antonio J. Osuna-Mascaró \\ Messerli Research Institute \\ University of Veterinary Medicine Vienna
}

\begin{abstract}
In their target article, Mikhalevich \& Powell (M\&P) argue that we should extend moral protection to arthropods. In this commentary, we show that there are some unforeseen obstacles to applying the sort of individualistic welfare-based ethics that M\&P have in mind to certain arthropods, namely, insects. These obstacles have to do with the fact that there are often many more individuals involved in our dealings with insects than our ethical theories anticipate, and also with the fact that, in some sense, some insects count as more than an individual and, in another sense, they sometimes count as less than an individual.
\end{abstract}

Susana Monsó is a philosopher working at the intersection of animal cognition and animal ethics. She is currently a post-doctoral research fellow at the Unit of Ethics and Human-Animal Studies of the Messerli Research Institute and leads a Lise Meitner project on Animals and the Concept of Death. Website

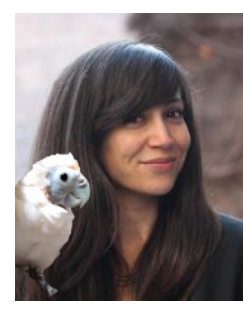

Antonio J. Osuna-Mascaró holds a PhD in Paleontology from the University of Granada and is currently a PhD candidate at the Unit of Comparative Cognition of the Messerli Research Institute, where he is working on unveiling the tooling abilities of Goffin's cockatoos. Website

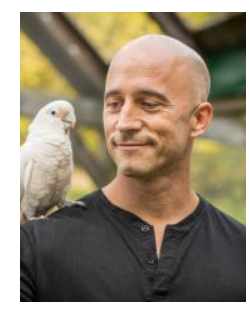

In their target article, Mikhalevich \& Powell (2020) (M\&P) argue against the blanket exclusion of arthropods from bioethics and science policy. They identify four obstacles that those seeking to integrate arthropods into our moral considerations must overcome: (1) an outdated but generalised view of them as lower on the scala naturae; (2) empirical uncertainties surrounding their sentience; (3) cognitive-affective biases that make humans view them as disgusting or unworthy of moral consideration; and (4) a widespread tendency to give more weight to scientific uncertainty than to moral risk. In this commentary, we focus on the specific case of insects and argue that their biology and ecology generate further obstacles that will have to be dealt with by any individualistic welfare-based ethical theory that aims to integrate them. 
Nonhuman animal ethics emerged from human ethics, through a process of expanding the circle of moral consideration (Singer, 2011). If one turns to the canonical texts, the main argument in them is one of consistency: one cannot consistently grant moral standing to all humans without granting it to at least some animals (Regan, 2004; Singer, 2009). M\&P also appeal to the principle of consistency in their target article: given what we accept as evidence of sentience in vertebrates, and consequently the grounds on which we grant them moral standing, we are warranted in erring on the side of caution with regard to arthropods. This common strategy is not only applied when we ask who is to be accorded moral standing: The question of the sort of treatment that animals are owed also tends to be modelled on how we think we ought to treat other humans. In the human case, we establish how we ought to treat each other not just on the basis of our sentience, but also on the basis of our interests. While for some ethicists these interests are always considered to have a subjective correlate in the form of preferences, other ethicists speak of objective interests that don't always have a subjective correlate, such that there can be harms that are not 'felt' (Crisp 2017). Regardless of whether welfare is understood as purely subjective or as having objective elements, human ethics is based on the idea that humans have interests that ought to be respected, since their satisfaction or frustration influences our welfare. Standard animal ethics extends this to other animals through an appeal to consistency. If animals have a (purely subjective or also objective) welfare and they have interests, then these interests ought to be included in our moral calculations, for consistency, and the issue then becomes how to balance their interests against our own.

The sort of ethics we are referring to, which dominates discussions on animal ethics and is also the kind of ethics that M\&P have in mind, is one that is both individualistic and welfarebased. In it, the realm of beings with moral standing is conceived as consisting of individuals. Other things being equal, each individual of a certain kind counts as one and none as more than one, and each has an interest-based welfare that can be affected by our actions (Monsó \& Grimm, 2019). Ethical theory is meant to provide us with guidance on how to navigate a world of such beings. The extension of this sort of individualistic welfare-based ethics to other species works well when we are dealing with mammalian or avian species, which are sufficiently similar to our own to warrant modelling ethical treatment of them on our ethical treatment of each other. This becomes more and more problematic the further we move from our own species. In the specific case of insects, they are not only very distant from us on the phylogenetic tree; they also have certain characteristics that make this sort of ethics not easily applicable to them. Arguing that they should be considered sentient, as M\&P do, can only get us as far as determining that they have moral standing, which simply means that we need to take them into account in our moral deliberations. In order to establish how we ought to treat them, standard animal ethics requires that we find a way of fitting them into an individualistic welfare-based paradigm. This, as we will argue, is not as easy as it may initially sound.

The first obstacle to expanding an individualistic welfare-based ethics to insects is the numbers involved. Most insects can be categorised as $r$-strategists, which means that a relatively high number of offspring compensates for the low energy investment that parents devote to each individual. This entails that insects have a very high reproductive capacity. Certain African termite queens can lay up to 43,000 eggs in a single day, one every two seconds, uninterruptedly (Klowden, 2013). Humans exploit this high reproductivity when breeding insects; conditions in captivity can be adjusted so that many more offspring survive than would in the wild. Insects are 
also an extremely abundant form of life, to the extent that they represent at least $80 \%$ of all known animal species. Insect numbers are so vast that we normally refer to number of species, where over a million of them have been described, but it has been estimated that there are at least 4.5 million more (Stork, 2018). The number of individuals is ungraspable, with an estimate of $10^{18}$ being alive at any given time (Williams, 1960). Given the rate at which we breed them and the worrying extent to which we affect their lives in the wild, between human-driven habitat loss; pollution; climate change; pesticides; fertilisers; and the introduction of competitive, predatory, and parasitic species (Sánchez-Bayo \& Wyckhuys, 2019), the number of insects that we routinely harm will easily be up in the trillions.

In animal ethics, it is quite widely accepted that the numbers count, and many consider that negative and positive experiences can be aggregated, such that if one must choose between harming a few and harming many, one should opt for harming the few. The immense numbers involved when discussing our dealings with insects can easily generate problems, given that our ethical theories were not designed with such numbers in mind. For example, in agriculture, some species of insect are used as biological control for eliminating pests. Before these insects are released onto the field, they are typically sterilised using X-rays. We don't know whether this procedure causes pain or stress to the animals. Supposing that it causes only a minor inconvenience to each animal, however, this could be considered a huge harm if we factor in the actual numbers, given that a facility breeding these insects can produce up to 5 billion individuals per week (Boppré \& Vane-Wright, 2019). Similarly, if we were to switch from conventional livestock to insects as a source of meat, as is being promoted by the FAO (Halloran \& Vantomme, 2013), the number of individuals affected by our farming practices, which is already immense, would skyrocket. For instance, one pig typically produces $16 \mathrm{~kg}$ of protein (Healthline, n.d.), whereas $100 \mathrm{~g}$ of cricket flour is equivalent to $76 \mathrm{~g}$ of protein and contains over 1100 crickets (Thailand Unique, n.d.). This means that one would need to raise and slaughter approximately 230,000 crickets to produce the same amount of protein as one single pig. If each insect's individual welfare is to count for one, as is the case in standard vertebrate ethics, then the sheer numbers involved might tip the scales in favour of sparing the insects rather than the mammals in many counterintuitive cases.

A second obstacle to expanding an individualistic welfare-based ethics to insects is that there are reasons to think that, in some cases and in a diachronic sense, insects should be considered as more than an individual. This has to do with the fact that a significant proportion of insects undergo metamorphosis during their lifetime. In some cases, in what is known as hemimetaboly, the metamorphosis is only partial, in that the initial and final stages look similar but only the adult can fly and reproduce. In other cases, however, we have holometaboly, which means that the metamorphosis is complete: the final creatures are radically different in their appearance, behaviour, and needs from what they initially were (Boppré \& Vane-Wright 2019). Holometabolous insects in their adult stage have a completely different set of interests, and thus a different welfare, than they do in their larval stage. They are, in a clear sense, a different individual. This adds complications to any moral calculation involving holometabolous insects that our individualistic theories are not prepared for. The ethical significance of ending the life of holometabolous insects in their larval or pupal stage might not be so easy to account for with our current theories on the ethics of killing animals. It might be better to kill a larva than a fully-formed beetle, since the former is less cognitively sophisticated. But one could also argue that preventing 
larvae from reaching their 'higher self' adds an extra dimension of harm that an individualistic ethical theory cannot straightforwardly capture.

A third obstacle is that there are also reasons to think that, at least in some cases and in a synchronic sense, insects should be considered as less than an individual. We are thinking specifically of eusocial insects. It is common among entomologists to consider some insect colonies as superorganisms (Wheeler, 1911). Supraorganismal colonies are composed of individuals that act in concert to produce phenomena guided by the group as a whole (Holldobler \& Wilson, 2009). Physiological functions are divided among the colony members in a drastic and literal sense, with the most notorious case being reproduction, since only a certain number of individuals can reproduce, and the rest are sterile. This phenomenon is similar to what we can observe in our own bodies, where only gametes and not somatic cells are responsible for reproductive functions. In addition, the distribution of roles among castes in eusocial insects generates emergent adaptive behaviours. While the cognitive abilities of members of some species have been individually reduced with their evolution to eusociality (O'Donnell et al., 2015), the colony as a whole gained a degree of adaptiveness and problem-solving capacity that is unattainable by any of its members on their own. If we think of intelligence as the capacity to solve problems in a flexible way, the colony is in effect more intelligent than any of its members.

Supraorganismal colonies therefore exhibit a behavioural and physiological range that surpasses that of the individuals, and there is a clear sense in which the colonies themselves have a welfare of their own, in that they have interests that determine whether things go better or worse for them. The topology of an ants' nest can affect the colony's efficiency in exploiting environmental resources, and thus affects its overall welfare even though none of its individuals might feel a subjective decrease in welfare (Vaes et al., 2020). Moreover, the distribution of functions characteristic of superorganisms, as a consequence of kin selection, has enabled the development of adaptations that occasionally drive individual members to sacrifice their lives for the good of the colony. As in our own bodies, each of the living components that make up the superorganism sacrifice individuality and functionality as a result of the enormous proportion of genetic information shared with the other members. This gives us reasons to think that the ethical significance of harms done to eusocial insects cannot be straightforwardly modelled on the harms done to vertebrates. Eusocial insects routinely put the welfare of the colony before their own, and it might amount to nothing more than unwarranted anthropocentrism to force them into an individualistic welfare-based paradigm. Moreover, with the perspective of the colony in mind, each individual is not equivalent. It could be, for instance, a much graver wrong to kill a queen than to kill a worker.

We don't believe that any of these obstacles are insurmountable. However, they do entail that an individualistic welfare-based ethics may not be extendable in a straightforward way to insects, as it has been, for instance, in the case of other mammals. M\&P make a good case for granting moral standing to insects. But any ethical theory that also aims to give concrete guidance on how we should treat insects must be shaped with these further obstacles in mind. 


\section{References}

Boppré, M. and Vane-Wright, R. (2019) Welfare dilemmas created by keeping insects in captivity. In C. Carere and J. Mather (Eds.), The Welfare of Invertebrate Animals (pp. 23-67). Springer International Publishing.

Crisp, R. (2017) Well-Being. In N. Zalta (Ed.), The Stanford Encyclopedia of Philosophy. Metaphysics Research Lab, Stanford University.

Halloran, A. and Vantomme, P. (2013) The Contribution of Insects to Food Security, Livelihoods and the Environment.

Healthline. (n.d.) Pork 101: Nutrition Facts and Health Effects.

Holldobler, B. and Wilson, E.O. (1990) The Ants. Belknap Press: An Imprint of Harvard University Press.

Klowden, M. (2013) Physiological Systems in Insects. Elsevier.

Mikhalevich, I. and Powell, R. (2020) Minds without spines: Evolutionarily inclusive animal ethics. Animal Sentience 29(1).

Monsó, S. and Grimm, H. (2019) An alternative to the orthodoxy in animal ethics? Limits and merits of the Wittgensteinian critique of moral individualism. Animals 9(12) 1057.

O'Donnell, S., Bulova, S., DeLeon, S., Khodak, P., Miller, S. and Sulger, E. (2015) Distributed cognition and social brains: Reductions in mushroom body investment accompanied the origins of sociality in wasps (Hymenoptera: Vespidae). Proceedings of the Royal Society B: Biological Sciences 282(1810) 20150791.

Regan, T. (2004) The Case for Animal Rights. University of California Press.

Sánchez-Bayo, F. and Wyckhuys, K. (2019) Worldwide decline of the entomofauna: A review of its drivers. Biological Conservation 232 8-27.

Singer, P. (2009) Animal Liberation. Harper Perennial Modern Classics.

Singer, P. (2011) The Expanding Circle: Ethics, Evolution, and Moral Progress. Princeton University Press.

Stork, N. (2018) How many species of insects and other terrestrial arthropods are there on Earth? Annual Review of Entomology 63(1) 31-45.

Thailand Unique. (n.d.) Cricket Powder: Acheta Domesticus 100g.

Vaes, O., Perna, A. and Detrain, C. (2020) The effect of nest topology on spatial organization and recruitment in the red ant Myrmica rubra. The Science of Nature 107(3) 23.

Wheeler, W.M. (1911) The ant-colony as an organism. Journal of Morphology 22 307-325. Williams, C.B. (1960) The range and pattern of insect abundance. The American Naturalist 94(875) 137-151. 


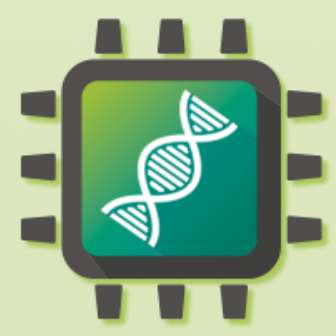

\section{Summer School 2020}

INNOVATIVE SCIENCE WITHOUT ANIMALS

June 22-26, 2020

\section{Online Virtual Conference}

\section{Calling all students and early-career researchers!}

Join us for a FREE conference on innovative approaches in toxicology and biomedical sciences!

\section{This event features:}

- Lecture sessions about modern alternatives to the use of animals in toxicology and biomedical sciences

Virtual laboratory tours

E-poster presentations

Virtual engagement with speakers and attendees

Deadline to apply for the full program is June 10. Registration for individual lectures is available.

For more information visit InnovativeScience2020.org

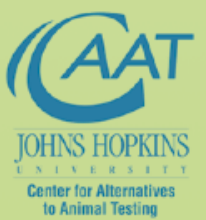

Physicians

committee

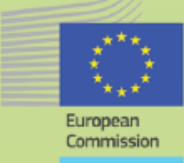

